\title{
MOLECULAR DOCKING ANALYSIS OF THIRTEEN COMPOUNDS AS MODULATOR OF IONOTROPIC GLUTAMATE RECEPTOR
}

\author{
RADHAKRISHNAN NARAYANASWAMY1,2*, MERRY HAILU ${ }^{2}$ \\ ${ }^{1}$ Bio-Incubator and Lab, Vel Tech Technology Incubator, Vel Tech Rangarajan Dr. Sagunthala R and D Institute of Science and Technology, \\ 400 Feet Outer Ring Road, Avadi, Chennai - 600 062, Tamil Nadu, India. ${ }^{2}$ Department of Biotechnology, Vel Tech Rangarajan Dr. Sagunthala \\ R and D Institute of Science and Technology, Avadi, Chennai - 600 062, Tamil Nadu, India. \\ Email: drradhakrishnan@veltech.edu.in
}

Received: 30 May 2018, Revised and Accepted: 29 July 2018

\section{ABSTRACT}

Objectives: Ionotropic glutamate receptors (iGluRs) play a key role in the development and function of the nervous system. They also play an important in memory and learning process. They are implicated in various pathological conditions such as Alzheimer's, Epilepsy, Huntington's, and Parkinson's diseases. This prompted us to carry out the present study on 13 selected compounds.

Methods: These 13 compounds were evaluated on the docking behavior of iGluR-2 (iGluR2) using PatchDock. In addition, molecular physicochemical, drug-likeness, absorption, distribution, metabolism, and excretion analyses were also carried out.

Results: The molecular physiochemical analysis revealed that all the 13 ligands showed nil violation and complied well with the Lipinski's rule of five. ADME analysis showed that all the ligands (except ligands 1 and 12) predicated to have high gastrointestinal absorption property. Docking studies revealed that ligand 8 (dopamine) showed the highest atomic contact energy (ACE) (-78.14 kcal/mol), while ligand 9 (6-hydroxydopamine) showed the least ACE $(-14.34 \mathrm{kcal} / \mathrm{mol})$ with that of iGluR2. Similarly, ligand 8 (dopamine) has shown to interact with Ser 142 amino acid residue of iGluR2.

Conclusion: Thus, the present study showed the potential of 13 compounds as a modulator of iGluR-2.

Keywords: Ionotropic glutamate receptors, Docking, Dopamine, 6-hydroxydopamine, L-Glutamate, L-beta-oxalyl-amino-alanine.

(C) 2018 The Authors. Published by Innovare Academic Sciences Pvt Ltd. This is an open access article under the CC BY license (http://creativecommons. org/licenses/by/4. 0/) DOI: http://dx.doi.org/10.22159/ajpcr.2018.v11i11.27602

\section{INTRODUCTION}

L-Glutamate is the primary excitatory neurotransmitter in the mammalian central nervous system (CNS). L-Glutamate employs its action through metabotropic (mGluRs) and ionotropic (iGluRs) receptors. The metabotropic receptors (mGluRs) are G protein-coupled receptors type which plays modulators role in the CNS, whereas ionotropic receptors (iGluRs) mediate fast synaptic transmission through ligand-gated ion channels. The metabotropic receptors (mGluRs) are sub-divided into three groups, they are Group 1 receptors (mGlu1, 5R) activate phospholipase $C$ enzyme activity, while Group 2 (mGlu2, 3R) and Group 3 (mGlu4, 6, 7, 8R) inhibit adenylyl cyclase activity when expressed in heterologous system. The ionotropic receptors (iGluRs) are classified into three sub-types; they are N-Methyl-DAspartate (NMDA) receptors, N-Amino-3-hydroxy-5-methyl-4-isoxazole propionic acid (AMPA) receptors, and 2-Carboxy-3-carboxymethyl-4isopropenylpyrrolidine (kainite, KA) receptors. Apart from these, there are also two glutamate delta receptors, namely GluD1 and GluD2 [1]. Naur et al. [2] reported that seven subunits of NMDA subtype (GluN1, GluN2A-GluN2D. GluN3A-GluN3B), four subunits of AMPA subtype (GluA1-GluA4), and five subunits of KA subtype (GluK1 GluK5).

The ionotropic receptors (iGluRs) play a key role in the development and function of the nervous system including brain function. They also involved in numerous neurodegenerative diseases such as Alzheimer's disease (AD), Parkinson's disease, schizophrenia, brain damage followed by epilepsy and stroke, as well as in the process of learning and memory [3]. The ionotropic receptors (iGluRs) are potential therapeutic drug targets/biomarker for various neurological disorders. In recent years, very good progress has been made in structure elucidation and understanding of ionotropic receptors (iGluRs) functions [1]. This prompts us to carry out the present study where, we have selected 13 compounds they are (1) L-beta-oxalyl-aminoalanine (L-BOAA), (2) L-beta-methylamino-L-alanine (L-BMAA), (3) L-2,3-diaminopropionic acid, (4) 2,3-diaminobutanoic acid, (5) L-2,4-diaminobutyric acid, (6) 4-aminobutyric acid, (7) glutamate, (8) dopamine, (9) 6-hydroxydopamine (6-HOD), (10) betacyanoalanine, (11) N-methyl-D-aspartic acid, (12) monosodium L-glutamate (MSG), and (13) cyperquat (or) 1-Methyl-4phenylpyridinium $\left(\mathrm{MPP}^{+}\right)$were evaluated on the docking behavior of ionotropic glutamate receptor-2 (iGluR2) using PatchDock. In addition, molecular physicochemical, drug-likeness, absorption, distribution, metabolism, and excretion analyses (ADME) were also carried out. The result shows that the potential of 13 compounds as iGluR2 modulators.

\section{METHODS}

\section{Ligand preparation}

Chemical structures of the ligands, namely (1) L-beta-oxalylamino-alanine (CID 2360); (2) L- beta-methylamino-Lalanine (CID 105089); (3) L-2,3-diaminopropionic acid (CID 97328); (4) 2,3-diaminobutanoic acid (ChemSpider ID 4475641); (5) L-2,4-diaminobutyric acid (CID 134490); (6) 4-aminobutyric acid (CID 119); (7) glutamate (CID 104813); (8) dopamine (CID 681); (9) 6-HOD (CID 4624); (10) beta-cyanoalanine (CID 13538); (11) N-methyl-D-aspartic acid (CID 22880); (12) MSG (ChemSpider ID 76943); and (13) $\mathrm{MPP}^{+}$(CID 39484) were retrieved from PubMed (www.pubmed.com) compound and ChemSpider (www.chemspider.com) compound database, respectively.

Target protein identification and preparation

The three dimensional structures of the iGluR2 (PDB ID: 3RN8 with resolution of $1.7 \mathrm{~A})$ were obtained from the Research Collaboratory 
for Structural Bioinformatics Protein Data Bank (www.rcsb.org) [4]. A chain of this protein was processed individually by removing another chain (B, C, and D), ligands in addition to the crystallographically observed water particles (water without hydrogen bonds). The protein mentioned above was prepared using UCSF Chimera software (www cgi.ucsf.edu/chimera).

\section{ADME analysis}

ADME analysis was performed by Swiss ADME analysis was carried by a standard default protocol [5].

\section{Docking studies}

Docking studies were carried out by the PatchDock online server (http://bioinfo3d.cs.tau.ac.il/PatchDock). PatchDock adopts geometrybased molecular docking algorithm method was used to recognize the binding scores, by binding residues atomic contact energy (ACE) of the given ligands [6]. The docking results were obtained through the email address. We also use to get a uniform resource locator which provides the top 20 solutions in a table form through email. From these, the top one solution (the docked protein-ligand complex) was selected and downloaded in a database (pdb) file format. Further, the binding site analysis was carried out by PyMOL software (www.pymol.org).

\section{RESULTS AND DISCUSSION}

Olney et al. [7] related the neurotoxic action of glutamic acid to its excitatory effects. This gives rise to frame new concept called "excitotoxin." According to this report, acidic amino acids have possessed strong neuroexcitatory effects and cause neuronal degeneration by excessive depolarizing neurons through specific receptors responsive to these amino acids [7]. Neuronal death is nothing but excitotoxicity which is induced by excessive stimulation of neuronal glutamate receptors [8]. For example, ischemia is commonly caused due to neuronal activation, which in turn results in increased glutamate release.

The above background prompted us to carry out the present study on 13 selected compounds. These 13 compounds were evaluated on the docking behavior of iGluR2 using PatchDock. Lathyrism is a human neurological disorder caused due to excessive intake of plant toxin, L-BOAA present in Lathyrus sativus [9]. L-BMAA is another neurotoxin, commonly present in cyanobacteria, diatoms, and dinoflagellates which is associated with neurodegenerative diseases such as AD, amyotrophic lateral sclerosis, and Parkinson's disease [10]. Several toxicant-induced Parkinson's disease model has been reported which includes toxicants such as 6-HOD, 1-methyl-4-phenyl-1, 2, 3, 6-tetrahydropyridine (MPTP), paraquat, and rotenone [11,12]. $\alpha$, $\beta$-Diamino acids are well known among the non-proteinogenic amino acids due to their abundant availability in nature [13]. Especially, L-2, 3-diaminopropionic acid is a precursor of antibiotics and staphyloferrin B (a siderophore produced by Staphylococcus aureus)
[14]. Similarly 2, 3-Diaminobutanoic acids have well known to be part of few peptide antibiotics and toxins [13]. Craighead et al. (2009) had reported the presence of 2, 4-diaminobutyric acid (neurotoxic amino acid) in shallow springs of Gobi desert, Mongolia [15]. 6-OHDA is neurotoxic amino acid, which structural resemble with that of dopamine, catecholamines, and noradrenaline [16]. NMDA has been reported from various animal phyla such as amphibians (Rana esculenta), arthropods, birds (Gallus gallus), chordates, cephalopod (Octopus vulgaris), crustacean (Carcinus maenas), mammals (Rattus norvegicus), mollusks, ray fish (Torpedo ocellata), and tunicates (Ciona intestinalis) [17]. MSG is the sodium salt of glutamic acid. The intake of MSG is associated with metabolic dysfunction, neuroendocrine disorders, oxidative stress, learning, and memory deficit [18]. MPP ${ }^{+}$ is the toxic metabolite of MPTP which induces apoptosis in cerebellar granule neurons [19]. The molecular physicochemical and druglikeness properties of 13 selected compounds were carried out using Molinspiration online software tool. In the present study, all the ligands exhibited nil violation and complied well with the Lipinski's rule of five as shown in Table 1.

With regard to drug-likeness score, all the ligands showed active to moderate active score towards all the six descriptions. Interestingly, none of them showed inactive score as shown in Table 2.

ADME is important screening tool which is employed in the early stage of drug discovery, drug design and drug screening, due to its unique characteristic nature [20]. Table 3 showed the ADME profile of the 13 selected compounds; all the ligands [except 1 (L-betaoxalyl-amino alanine) and 12 (MSG)] are predicted to have high gastrointestinal absorption effect.

The glutamate receptors (GluRs) have been reported to regulate cytokine, immune responses, matrix metalloproteinase release, peripheral pain, and synoviocyte proliferation. Thus, a glutamate receptor (GluR) antagonist acts as a potential drug with multimodal activity against arthritis [21]. The ionotropic receptors (iGluRs) play a key role in synaptic transmission and are reported in the post-synaptic neural membrane [22]. Therefore, both the physiological and pathological roles of iGluRs have been detailed studied using molecular and pharmacological approaches [23]. Docking studies revealed that ligand 8 (Dopamine) showed the highest ACE $(-78.14 \mathrm{kcal} / \mathrm{mol})$, while ligand $9(6-\mathrm{HOD})$ showed the least ACE $(-14.34$ $\mathrm{kcal} / \mathrm{mol}$ ) with that of iGluR2 as shown in Table 4.

The binding affinities of the 13 ligands to iGluR2 exhibited the following order ligand 8 (Dopamine) > ligand 1 (L-beta-oxalyl-amino-alanine) $>$ ligand 10 (Beta-cyanoalanine) > ligand 6 (4-Aminobutyric acid) > ligand 2 (L- beta-methylamino-L-alanine) $>$ ligand $12(\mathrm{MSG})>$ ligand $13\left(\mathrm{MPP}^{+}\right)>$ligand 11 (N-methyl-D-aspartic acid) > ligand 3 (L-2,3Diaminopropionic acid) $>$ ligand 4 (2,3-diaminobutanoic acid) $>$ ligand 7 (Glutamate) > ligand 5 (L-2,4-diaminobutyric acid) > ligand 9 (6 HOD)

Table 1: Molecular physicochemical descriptors analysis of 13 compounds using Molinspiration online software tool

\begin{tabular}{|c|c|c|c|c|c|c|c|c|c|}
\hline Ligands & $\log A^{a}$ & TPSA $^{\mathrm{b}}$ & Natoms $^{c}$ & $\mathbf{M W}^{\mathrm{d}}$ & $\mathrm{noN}^{\mathrm{e}}$ & nOH NH ${ }^{f}$ & Nviolations $^{\mathrm{g}}$ & Nrotb $^{h}$ & Volume $^{\mathrm{i}}$ \\
\hline 1 & -4.52 & 129.72 & 12 & 176.13 & 7 & 5 & 0 & 4 & 142.94 \\
\hline 2 & -3.25 & 75.35 & 8 & 118.14 & 4 & 4 & 0 & 3 & 113.52 \\
\hline 3 & -4.21 & 89.34 & 7 & 104.11 & 4 & 5 & 0 & 2 & 95.84 \\
\hline 4 & -3.83 & 89.34 & 8 & 118.14 & 4 & 5 & 0 & 2 & 112.43 \\
\hline 5 & -3.96 & 89.34 & 8 & 118.14 & 4 & 5 & 0 & 3 & 112.64 \\
\hline 6 & -1.10 & 63.32 & 7 & 103.12 & 3 & 3 & 0 & 3 & 101.33 \\
\hline 7 & -4.41 & 103.45 & 10 & 146.12 & 5 & 3 & 0 & 4 & 125.61 \\
\hline 9 & -0.13 & 86.71 & 12 & 169.18 & 4 & 5 & 0 & 2 & 152.99 \\
\hline 10 & -3.58 & 87.11 & 8 & 114.10 & 4 & 3 & 0 & 2 & 101.41 \\
\hline 11 & -2.61 & 86.62 & 10 & 147.13 & 5 & 3 & 0 & 4 & 129.23 \\
\hline 12 & -3.70 & 107.90 & 10 & 146.12 & 5 & 3 & 0 & 4 & 123.67 \\
\hline 13 & -2.73 & 3.88 & 13 & 170.24 & 1 & 0 & 0 & 1 & 171.09 \\
\hline
\end{tabular}

${ }^{\mathrm{a}}$ Octanol-Water partition coefficient, ${ }^{\mathrm{b}}$ Polar surface area, ${ }^{\mathrm{c}}$ number of non-hydrogen atoms, ${ }^{\mathrm{d}}$ molecular weight, ${ }^{\mathrm{e}}$ number of hydrogen bond acceptors [0 and $\mathrm{N}$ atoms], ${ }^{\mathrm{f}}$ number of hydrogen bond donors [OH and $\mathrm{NH}$ groups], " nnumber of rule of 5 violations, ${ }^{\text {hnumber }}$ of rotatable bonds, ${ }^{\mathrm{i}}$ molecular volume 
Table 2: Drug-likeness property analysis of 13 compounds analogs using Molinspiration tool

\begin{tabular}{|c|c|c|c|c|c|c|}
\hline Ligands & $\begin{array}{l}\text { GPCR* } \\
\text { ligand }\end{array}$ & $\begin{array}{l}\text { Ion channel } \\
\text { modulator }\end{array}$ & $\begin{array}{l}\text { Kinase } \\
\text { inhibitor }\end{array}$ & $\begin{array}{l}\text { Nuclear receptor } \\
\text { ligand }\end{array}$ & $\begin{array}{l}\text { Protease } \\
\text { inhibitor }\end{array}$ & $\begin{array}{l}\text { Enzyme } \\
\text { inhibitor }\end{array}$ \\
\hline 1 & -0.23 & 0.11 & -0.80 & -0.73 & 0.20 & 0.23 \\
\hline 2 & -2.10 & -1.70 & -2.79 & -3.07 & -1.82 & -2.00 \\
\hline 3 & -2.48 & -2.29 & -3.04 & -3.28 & -2.14 & -2.38 \\
\hline 4 & -2.52 & -2.13 & -3.18 & -2.88 & -2.06 & -2.24 \\
\hline 5 & -1.91 & -1.40 & -2.69 & -3.02 & -1.60 & -1.67 \\
\hline 6 & -2.59 & -2.61 & -3.29 & -3.06 & -2.40 & -2.46 \\
\hline 8 & -0.44 & 0.01 & -0.65 & -0.98 & -0.67 & -0.16 \\
\hline 9 & -0.38 & -0.01 & -0.49 & -0.74 & -0.65 & -0.07 \\
\hline 10 & -2.62 & -2.21 & -3.21 & -3.28 & -1.94 & -2.15 \\
\hline 11 & -0.29 & 0.13 & -1.29 & -1.12 & -0.13 & 0.01 \\
\hline 12 & -0.87 & -0.10 & -1.26 & -1.49 & -1.27 & -0.55 \\
\hline 13 & -0.37 & 0.32 & -0.84 & -2.03 & -0.57 & 0.19 \\
\hline
\end{tabular}

Table 3: ADME analysis of 13 compounds using Swiss ADME online tool

\begin{tabular}{|c|c|c|c|c|c|c|c|c|c|}
\hline Ligands & $\mathbf{G l}^{\bullet}$ & BBB $^{\#}$ & P-gp ${ }^{0}$ & CYP1A2* & CYP2C19* & CYP2C9* & CYP2D6* & CYP3A4* & $\log K p$ \\
\hline 1 & Low & No & No & No & No & No & No & No & -10.28 \\
\hline 2 & High & No & No & No & No & No & No & No & -9.71 \\
\hline 3 & High & No & No & No & No & No & No & No & -10.00 \\
\hline 4 & High & No & No & No & No & No & No & No & -9.29 \\
\hline 5 & High & No & No & No & No & No & No & No & -10.32 \\
\hline 6 & High & No & No & No & No & No & No & No & -9.18 \\
\hline 7 & High & No & No & No & No & No & No & No & -9.81 \\
\hline 9 & High & No & No & No & No & No & No & No & -7.20 \\
\hline 10 & High & No & No & No & No & No & No & No & -9.61 \\
\hline 11 & High & No & No & No & No & No & No & No & -9.58 \\
\hline 12 & Low & No & Yes & No & No & No & No & No & -9.95 \\
\hline 13 & High & Yes & No & No & No & No & No & No & -9.57 \\
\hline
\end{tabular}

$\bullet:$ Gastrointestinal, \#: Blood-brain barrier permeant, : P-gp-P-glycoprotein substrate, *: CYP-Cytochrome P450 Inhibitors, ^: Skin permeation (cm/s)

Table 4: The interaction energy analysis of 13 compounds with iGluR2 using PatchDock

\begin{tabular}{|c|c|c|c|}
\hline Ligand & -ACE (kcal/mol) & Interaction of amino acid residue & Bond distance $(\AA ̊)$ \\
\hline \multirow[t]{3}{*}{1} & 67.39 & Leu94 & 2.71 \\
\hline & & Ser142 & 3.16 \\
\hline & & Lys218 & 2.68 \\
\hline \multirow[t]{3}{*}{2} & 58.51 & Leu94 & 3.30 \\
\hline & & Val95 & 3.52 \\
\hline & & Arg149 & 3.40 \\
\hline 3 & 21.21 & No interaction & - \\
\hline \multirow[t]{2}{*}{4} & 19.09 & Arg64 & 2.83 and 2.89 \\
\hline & & Glu145 & 3.37 \\
\hline 5 & 15.22 & Arg64 & 3.12 \\
\hline 6 & 59.66 & Lys157 & 2.97 and 3.19 \\
\hline \multirow[t]{3}{*}{7} & 16.96 & Arg64 & 3.11 \\
\hline & & Glu145 & 2.63 and 3.23 \\
\hline & & $\operatorname{Arg} 148$ & 2.94 \\
\hline 8 & 78.14 & Ser142 & 3.09 \\
\hline 10 & 63.95 & No interaction & - \\
\hline \multirow[t]{2}{*}{11} & 22.70 & Glu145 & 2.18 and 3.31 \\
\hline & & Arg149 & 2.15 \\
\hline 12 & 44.48 & Phe102 & 3.12 \\
\hline 13 & 35.15 & No interaction & - \\
\hline
\end{tabular}

*ACE: Atomic contact energy, iGluR2: Ionotropic glutamate receptor-2

In the present study, interaction with Ser142 amino acid residue has been shown by two ligands such as ligand 1 (L-beta-oxalyl-aminoalanine) and ligand 8 (dopamine). The present finding was in good agreement with an earlier report [4].

\section{CONCLUSION}

In the present study, all the tested ligands have shown to dock with the target protein (iGluR2). However, ligand 3 (L-2,3diaminopropionic acid), ligand 10 (Beta-cyanoalanine), and 
ligand $13\left(\mathrm{MPP}^{+}\right)$do not interact with any amino acid residues of the target protein (iGluR2). Thus, the present study showed the potential of 13 compounds as a modulator of iGluR2.

\section{ACKNOWLEDGMENT}

The authors express their sincere gratitude to the authority of Vel Tech Rangarajan Dr. Sagunthala R and D Institute of Science and Technology, Chennai, for providing research facilities.

\section{AUTHOR'S CONTRIBUTIONS}

RN (first author), who had wrote the manuscript and submitted the same. Merry (research scholar), who had contribute value to it. All authors read and approved the final manuscript.

\section{CONFLICTS OF INTEREST}

The authors have declared no conflicts of interest.

\section{REFERENCES}

1. Kaczor AA, Matosiuk D. Molecular structure of ionotropic glutamate receptors. Curr Med Chem 2010;17:2608-35.

2. Naur P, Hansen KB, Kristensen AS, Dravid SM, Pickering DS, Olsen L, et al. Ionotropic glutamate-like receptor delta2 binds D-serine and glycine. Proc Natl Acad Sci U S A 2007;104:14116-21.

3. Serafimoska Z, Johansen TN, Frydenvang K, Suturkova L. Ionotropic glutamate receptors (iGluRs): Overview of iGluR2 ligand binding domain in complex with agonists and antagonists. Maced Pharm Bull 2011;57:3-16.

4. Ankulu M, Aparna.N, Raju NV, Arjun LK. Putative ligand-target docking studies of human AMPA selective ionotropic glutamate receptors reveal that $\beta$-ODAP has high binding affinity compared to tyrosine and glutamate. Int Res J Biochem Bioinform 2013;3:130-9.

5. Daina A, Michielin O, Zoete V. Swiss ADME: A free web tool to evaluate pharmacokinetics, drug-likeness and medicinal chemistry friendliness of small molecules. Sci Rep 2017;7:42717.

6. Schneidman-Duhovny D, Inbar Y, Nussinov R, Wolfson HJ. PatchDock and symmDock: Servers for rigid and symmetric docking. Nucleic Acids Res 2005;33:W363-7.

7. Olney JW, Ho OL, Rhee V. Cytotoxic effects of acidic and sulphur containing amino acids on the infant mouse central nervous system. Exp Brain Res 1971;14:61-76.

8. Lipton P. Ischemic cell death in brain neurons. Physiol Rev 1999;79:1431-568

9. Pai KS, Ravindranath V. L-BOAA induces selective inhibition of brain mitochondrial enzyme, NADH-dehydrogenase. Brain Res 1993;621:215-21.

10. Jiang L, Kiselova N, Rosén J, Ilag LL. Quantification of neurotoxin BMAA ( $\beta$-N-methylamino-L-alanine) in seafood from Swedish markets. Sci Rep 2014;4:6931.

11. Rohini D, Vijayalakshmi K. Sesamol antagonizes rotenone-induced cell death in SH-SY5Y neuronal cells. Int J Pharm Pharm Sci 2016;8:72-7.

12. Priyanga KS, Vijayalakshmi K, Selvaraj R. Behavioral studies of wistar rats in rotenone induced model of parkinson's disease. Int J Pharm Pharm Sci 2017;9:159-64

13. Merino P, Lanaspa A, Merchan FL, Tejero T. Stereocontrolled synthesis of 2, 3-diaminobutanoic acids. Tetrahedron Lett 1997;38:1813-6.

14. Kobylarz MJ, Grigg JC, Shin-ichi JT, Rai DK, Heinrichs DE, Murphy ME. Synthesis of L-2, 3-diaminopropionic acid, a siderophore and antibiotic precursor. Chem Biol 2014;21:379-88.

15. Craighead D, Metcalf JS, Banack SA, Amgalan L, Reynolds HV, Batmunkh M. Presence of the neurotoxic amino acids $\beta-N-$ methylamino-L-alanine (BMAA) and 2, 4-diamino-butyric acid (DAB) in shallow springs from the Gobi Desert. Amyotroph Lateral Scler 2009; 10 sup2:96-100.

16. Simola N, Morelli M, Carta AR. The 6-hydroxydopamine model of Parkinson's disease. Neurotox Res 2007;11:151-67.

17. D'Aniello S, Fisher GH, Topo E, Ferrandino G, Garcia-Fernàndez J, D'Aniello A, et al. N-methyl-D-aspartic acid (NMDA) in the nervous system of the amphioxus branchiostoma lanceolatum. BMC Neurosci 2007;8:109.

18. Ganesan K, Sukalingam K, Balamurali K, Alaudeen SR, Ponnusamy K, Ariffin IA, et al. A studies on monosodium 1-glutamate toxicity in animal models-a review. Int J Pharm Chem Biol Sci 2013;3:1257-68.

19. Shang T, Uihlein AV, Van Asten J, Kalyanaraman B, Hillard CJ. 1-Methyl-4-phenylpyridinium accumulates in cerebellar granule neurons via organic cation transporter 3. J Neurochem 2003;85:358-67.

20. Wang J, Urban L. The impact of early ADME profiling on drug discovery and development strategy. DDW 2003;5:73-96.

21. Bonnet CS, Williams AS, Gilbert SJ, Harvey AK, Evans BA, Mason DJ, et al. AMPA/kainate glutamate receptors contribute to inflammation, degeneration and pain related behaviour in inflammatory stages of arthritis. Ann Rheum Dis 2015;74:242-51.

22. Dingledine R, Borges K, Bowie D, Traynelis SF. The glutamate receptor ion channels. Pharmacol Rev 1999;51:7-61.

23. Mayer ML, Armstrong N. Structure and function of glutamate receptor ion channels. Annu Rev Physiol 2004;66:161-81. 